\title{
Thoracic gas volume in early childhood
}

\author{
D. J. HATCH and B. W. TAYLOR \\ From the Departments of Respiratory Function and Anaesthesia, The Hospital for Sick Children, Great Ormond \\ Street, London
}

\begin{abstract}
Hatch, D. J., and Taylor, B. W. (1976). Archives of Disease in Childhood, 51, 859. Thoracic gas volume in early childhood. A total body plethysmograph is described which was used to study thoracic gas volume (TGV) in infants and young children from birth to $2 \frac{1}{2}$ years, and was suitable for use even in very sick babies. Normal TGV values were obtained in $\mathbf{4 2}$ studies of 35 healthy infants and young children, and 16 children with abnormal lung volume are described. TGV correlated well with length, weight, chest circumference, and age in the healthy infants. A low TGV was found in children with respiratory difficulties after cardiac and thoracic surgery, in respiratory distress syndrome of the newborn, and in association with pulmonary infection and chest cage abnormalities. Abnormally high TGV was most frequently seen in infants with small airways disease.
\end{abstract}

Many chronic respiratory diseases of childhood such as asthma and cystic fibrosis may cause symptoms during the first 1-2 years of life. Acute respiratory disease is often difficult to manage in this age group and may have sequelae which require long-term management. There is a need to assess the state of the respiratory tract objectively to follow the pattern of illness and to measure the response to different therapies.

Measurement of thoracic gas volume (TGV) by plethysmograph has been widely used in the assessment of respiratory function in the newborn, but there are few reports of its use in infancy and early childhood. We report details of a total body plethysmograph suitable for measuring TGV in children up to age $2 \frac{1}{2}$ years, with special features for use with very sick children. Normal values obtained in 35 infants and young children aged 4-16 months are given and TGV measurements in 16 children with abnormal lung function are also reported.

\section{Apparatus}

The plethysmograph is a modified Drinker ventilator with an internal volume of 1201 reducible to 451 by stages with solid formed inserts. It is portable, allowing studies on very sick infants to be made on the ward, allows easy observation, and the lid can be quickly released. Electrocardiographic leads are incorporated for

Received 1 March 1976. monitoring and a T-piece circuit can be attached to the airway to allow external control of the breathing for all but the few breaths necessary for the actual measurement.

The patient circuit (Fig. 1) was designed to have minimal dead space $(2-3 \mathrm{ml})$. The shutter mechanism is a rapidly inflatable rubber balloon. $A$ Fleisch $O$ pneumotachograph heated to $36^{\circ} \mathrm{C}$ allows measurement of flow and volume changes at the mouth. The resistance of this system is $7 \mathrm{~cm} \mathrm{H} \mathrm{H}_{2} \mathrm{O} / 1$ per s at $51 / \mathrm{min}$ flow. There is facility for oxygen supply and continuous positive airways pressure or intermittent positive pressure ventilation between measurements.

Plethysmograph pressure is monitored with an Elema Schonander EM32 pressure transducer placed inside the plethysmograph with a slow leak (time constant at least 3 seconds) on one side. This avoids drift due to temperature change in the plethysmograph and minimizes the effect of transient changes in barometric pressure. The plethysmograph pressure response is flat to 10 cycles $/ \mathrm{min}$ and with maximum sensitivity gives a full scale deflection with $5 \mathrm{ml}$ changes in plethysmograph volume.

Mouth pressure is monitored with an SE4-82 pressure transducer placed close to the patient inside the box. Flow and volume changes at the mouth are obtained by amplification and integration of the signal from the pneumotachograph via another EM32 transducer. An SE UV Recorder 3006 is used to give direct write out of the signals. A 5 th channel for oesophageal pressure is available.

To show the accuracy of the system tests were performed with a mechanical piston and syringe using glass flasks as simulated lungs. The flasks were packed with copper wire to reduce adiabasis (Mead, 1961). Using 


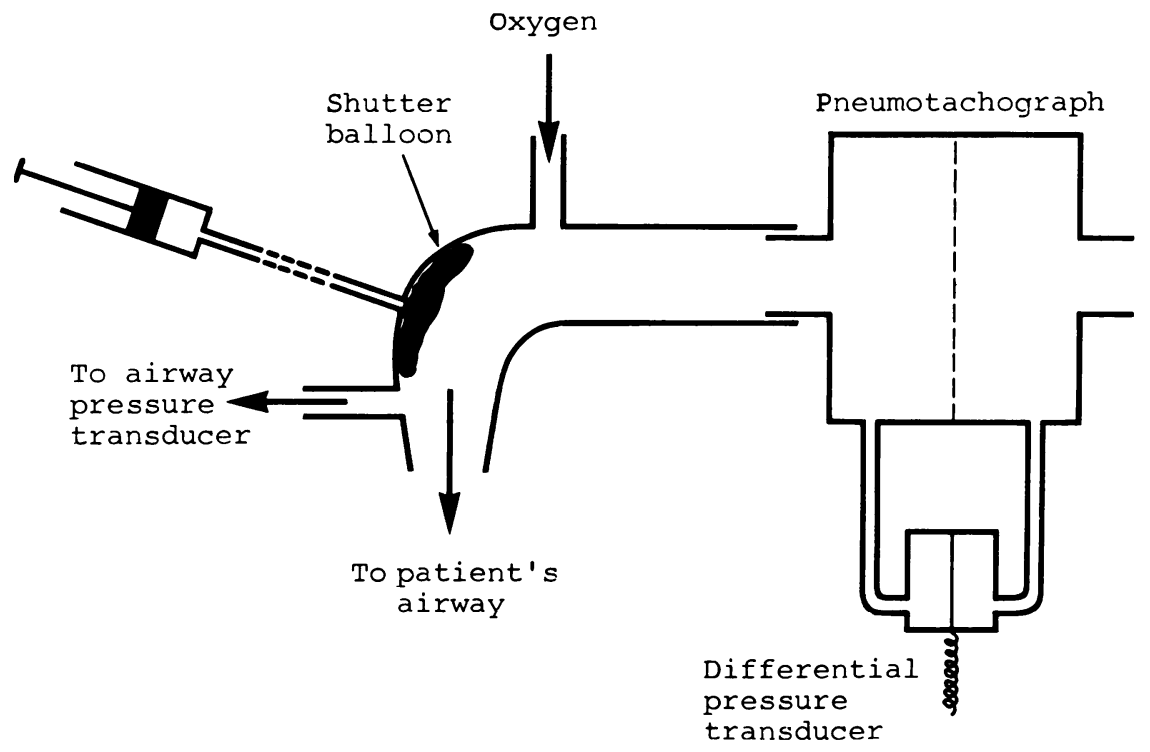

FIG. 1.-Patient circuit diagram.

3 different flask volumes (a) 460 , (b) 625 , (c) $1080 \mathrm{ml}$, values of (a) 450, (b) 607, and (c) $1050 \mathrm{ml}$ were obtained.

\section{Method}

TGV was measured by the method described by DuBois et al. (1956). The patient circuit was connected to the child either by a Rendell Baker face mask sealed to the face with putty, or via an endotracheal or tracheostomy tube already in situ. The shutter was closed as near as possible to end-expiration. Any minor adjustments to functional residual capacity were made by analysis of the volume tracing. The mean of results from at least 5 shutter closures was calculated.

TGV is calculated according to the formula:

$\mathrm{TGV}=\left(\mathbf{P}_{\mathrm{B}}-\mathbf{P}_{\mathrm{H}_{2} \mathrm{O}}\right) \times \Delta \mathrm{V} / \triangle \mathbf{P}$

where $\mathrm{P}_{\mathrm{B}}-\mathrm{P}_{\mathrm{H}_{2} \mathrm{O}}$ equals barometric pressure minus water vapour pressure in $\mathrm{cm} \mathrm{H}_{2} \mathrm{O}$. The ratio $\triangle \mathrm{V} / \triangle P$ is determined during shutter closure. Respiratory efforts cause compression and decompression $(\triangle \mathrm{P})$ of the air contained in the lung with a resultant volume change $(\triangle V)$. Pressure change is measured directly at the mouth and volume change is measured from pressure change in the plethysmograph, which is calibrated before and after the study by injecting known volumes $(5-10 \mathrm{ml})$ of air into it. This calibration is performed at approximately the respiratory rate of the subject to minimize errors from adiabatic effects, and 11 bags of fluid equal to the weight of the infant are placed in the plethysmograph during calibration.

\section{Subjects}

Thirty-five healthy young children age 4-16 months were studied while sedated with chloral $100 \mathrm{mg} / \mathrm{kg}$. These measurements were made as part of a study of children born to atopic parents (Taylor et al., 1973; Stokes, Taylor, and Turner, 1974). None of these children had developed respiratory symptoms up to 2 years later. Parental consent was obtained for this study, which was approved by the hospital ethical committee. 7 children were studied on 2 occasions.

TGV measurements are now made routinely whenever lung function studies are requested in babies up to $2 \frac{1}{2}$ years old. Results are given in the Table. The following case reports illustrate the value of TGV measurement. Some of these babies were in respiratory failure at the time of the study and were receiving ventilatory support with intermittent positive pressure ventilation from a mechanical ventilator or continuous positive airway pressure.

\section{Children with increased lung volume.}

Wilson-Mikity syndrome (Wilson and Mikity, 1960). Case 1. Born at 33 weeks' gestation; birthweight $1.0 \mathrm{~kg}$. Apgar score 3 at one minute, improving to 10 at 15 minutes, after initial tracheal intubation and ventilation. He developed increasing respiratory distress over the next 48 hours, requiring $40 \%$ oxygen to raise $\mathrm{PaO}_{2}$ to $100 \mathrm{mmHg}$. Chest $x$-ray showed a ground glass appearance. He slowly improved, but developed a mild respiratory infection at 3 weeks and a severe one at 4 months, when cystic changes were seen on chest $x$-ray. The findings of grossly increased TGV confirmed the severe lung damage, and he died of respiratory infection at age 6 months. Necropsy findings confirmed the diagnosis.

Aspiration lung disease (Williams, 1973). Case 2. Term, breech delivery; birthweight $2.5 \mathrm{~kg}$. Mild episode of tachypnoea at one month. Admitted to 
TABLE

Thoracic gas volume (TGV) in 28 studies on 16 young children with abnormal lung function

\begin{tabular}{|c|c|c|c|c|c|c|}
\hline Case no. & $\begin{array}{l}\text { Age } \\
(\mathrm{m})\end{array}$ & $\begin{array}{c}\text { Height } \\
\text { (cm) }\end{array}$ & $\begin{array}{c}\text { Weight } \\
\text { (kg) }\end{array}$ & $\begin{array}{l}\text { TGV } \\
(\mathrm{ml})\end{array}$ & $\underset{(\mathrm{ml})}{\mathrm{SD}}$ & $\begin{array}{c}\text { Mean } \\
\text { predicted } \\
\text { TGV }\end{array}$ \\
\hline $\begin{array}{l}\text { Increased TGV } \\
1 \mathrm{a} \\
\mathrm{b} \\
2 \mathrm{a} \\
\mathrm{b} \\
\mathrm{c} \\
\mathrm{d} \\
3 \\
4 \\
5 \\
6 \mathrm{a} \text { Supine } \\
\mathrm{b} \text { Left lateral } \\
\mathrm{c} \text { Supine } \\
7 \\
\text { Reduced TGV } \\
8 \\
9 \\
10 \\
11 \\
12 \\
13 \\
\text { Prolonged ventilation studies } \\
14 \mathrm{a} \\
\mathrm{b} \\
15 \mathrm{a} \\
\mathrm{b} \\
\mathrm{c} \\
\mathrm{d} \\
16 \mathrm{a} \\
\mathrm{b} \\
\mathrm{c}\end{array}$ & $\begin{array}{r}5 \\
6 \\
5 \\
6 \\
7 \\
15 \\
4 \\
17 \\
8 \\
9 \\
9 \\
12 \\
21 \\
\\
3 \\
3 \\
4 \\
16 \\
6 \\
3 \\
2 \\
4 \\
1 \mathrm{w} \\
2 \mathrm{w} \\
6 \mathrm{w} \\
3 \\
1 \\
2 \\
4 \\
\end{array}$ & $\begin{array}{l}51 \\
54 \\
63 \\
63 \\
65 \\
77 \\
68 \\
76 \\
70 \\
71 \\
71 \\
72 \\
79 \\
\\
54 \\
60 \\
65 \\
72 \\
53 \\
64 \\
\\
55 \\
56 \\
52 \\
52 \\
55 \\
57 \\
50 \\
50 \\
50\end{array}$ & $\begin{array}{r}2 \cdot 5 \\
2 \cdot 5 \\
5 \cdot 4 \\
5 \cdot 6 \\
6 \cdot 3 \\
9 \cdot 2 \\
8 \cdot 9 \\
9 \cdot 5 \\
7 \cdot 1 \\
9 \cdot 8 \\
9 \cdot 8 \\
10 \cdot 6 \\
10 \cdot 0 \\
\\
3 \cdot 9 \\
4 \cdot 1 \\
5 \cdot 1 \\
7 \cdot 7 \\
5 \cdot 0 \\
6 \cdot 9 \\
\\
4 \cdot 4 \\
5 \cdot 6 \\
3 \cdot 2 \\
3 \cdot 2 \\
3 \cdot 5 \\
3 \cdot 9 \\
3 \cdot 1 \\
3 \cdot 2 \\
3 \cdot 4\end{array}$ & $\begin{array}{r}258 \\
312 \\
247 \\
275 \\
293 \\
282 \\
433 \\
413 \\
415 \\
583 \\
469 \\
282 \\
400 \\
\\
66 \\
66 \\
75 \\
152 \\
44 \\
102 \\
\\
82 \\
378 \\
25 \\
35 \\
195 \\
187 \\
65 \\
80 \\
99\end{array}$ & $\begin{array}{r}26 \cdot 1 \\
14 \cdot 7 \\
13 \cdot 2 \\
18 \cdot 4 \\
14 \cdot 5 \\
5 \cdot 9 \\
46 \cdot 5 \\
28 \cdot 1 \\
17 \cdot 1 \\
61 \cdot 2 \\
44 \cdot 4 \\
18 \cdot 1 \\
12 \cdot 2 \\
\\
3 \cdot 5 \\
8 \cdot 1 \\
7 \cdot 0 \\
18 \cdot 6 \\
8 \cdot 5 \\
20 \cdot 1 \\
\\
4 \cdot 8 \\
12 \cdot 3 \\
5 \cdot 4 \\
1 \cdot 6 \\
2 \cdot 4 \\
4 \cdot 8 \\
3 \cdot 7 \\
2 \cdot 9 \\
4 \cdot 0\end{array}$ & $\begin{array}{l}139 \\
155 \\
205 \\
205 \\
216 \\
282 \\
232 \\
276 \\
243 \\
249 \\
249 \\
255 \\
293 \\
\\
155 \\
188 \\
216 \\
254 \\
150 \\
210 \\
\\
161 \\
166 \\
144 \\
144 \\
161 \\
172 \\
133 \\
133 \\
133\end{array}$ \\
\hline
\end{tabular}

hospital at 5 months with history of recurrent respiratory infections and failure to thrive. Scattered crepitations were heard throughout the chest, but chest $x$-ray was normal. Three serial TGV measurements showed increasing hyperinflation of the lungs. Sweat test was negative but fat-laden macrophages were seen in tracheal aspirate. Feeds were thickened and marked clinical improvement was noticed at once. Repeat TGV measured at 15 months was normal.

Asthma in infancy (Phelan and Williams, 1969b). Case 3. Born at 42 weeks' gestation; birthweight $3.9 \mathrm{~kg}$. Admitted to hospital at 4 months with 6-week history of recurrent cough and wheeze. Family history of allergy. Sweat test normal. TGV showed moderate hyperinflation. Adenovirus and cytomegalovirus isolated from nose. Repeat TGV measurements are planned.

Case 4. Born at 32 weeks' gestation; forceps delivery. Intubated and resuscitated at birth. History of recurrent cough and wheeze from early infancy. Family history of allergy. TGV showed overinflated lungs with normal airways resistance suggestive of small airways disease.

Laryngomalacia. Case 5. Admitted aged 8 months with history of frequent colds and attacks of 'noisy breathing'. Laryngoscopy showed laryngomalacia. Increased TGV compatible with airways obstruction. Gradually improving clinically. Follow-up TGV measurements are planned.

Lobar emphysema (Holzel, Bennett, and Vaughan, 1956). Case 6. Admitted aged 9 months with history of dyspnoea and wheezing. Chest $x$-ray showed a translucent left upper lobe and TGV was raised. After resection of the grossly emphysematous lobe TGV returned to normal.

Bronchopulmonary dysplasia (Northway, Rosan, and Porter, 1967; Becker and Koppe, 1969; Barnes et al., 1969). Case 7. A previously healthy, term infant developed respiratory syncytial virus pneumonia at age 5 months and received mechanical ventilation of the lungs for 10 weeks. Subsequently he gained weight and height but wheeze and stridor persisted. Despite clinical recovery, chest $x$-ray and TGV both showed persistent hyperinflation 1 year later. $X$-ray also showed an increase in bronchial vascular markings and suggested cyst formation. He remains well and active apart from mild respiratory tract infections.

Children with reduced lung volume.

(1) Postoperative. These children were all receiving 
intermittent positive pressure ventilation (IPPV) at the time of the study.

Cardiopulmonary bypass surgery. Case 8. Admitted in congestive cardiac failure at age 3 months for total correction of atrioventricular canal, having had banding of the pulmonary artery at age 2 weeks. Postoperative weaning from IPPV began uneventfully, but on the 4th postoperative day developed pulmonary oedema and IPPV was started. TGV was grossly reduced. Continuous positive airway pressure improved oxygenation but the infant died 2 days later. Post-mortem examination showed bilateral pneumonia and mitral incompetence.

Case 9. Correction of total anomalous pulmonary venous drainage at age 2 weeks. TGV normal one month after operation. Condition deteriorated 2 weeks later, and reoperated for pulmonary venous obstruction. Developed bilateral bronchopneumonia with reduced TGV and died after 2 months of IPPV. Necropsy examination showed persistent pulmonary venous obstruction and pulmonary fibrosis.

Case 10. Severe pulmonary stenosis with atrial septal defect repaired at age 4 months. Required IPPV postoperatively, and TGV on the 3rd postoperative day was reduced. Weaned successfully onto continuous positive airway pressure and extubated after 2 days.

Major noncardiac surgery. Case 11. Known case of oesophageal atresia. Admitted at age 15 months for colonic replacement of oesophagus. Developed postoperative pneumonia and respiratory failure requiring IPPV. Continuous positive airway pressure used because of reduced TGV, aided weaning from the ventilator, with marked increase in tidal volume and gas exchange.

(2) Chest cage abnormalities. Case 12. Achondroplastic baby with large ventricular septal defect causing congestive cardiac failure at age 2 weeks. Ventricular septal defect closed on cardiopulmonary bypass at 1 month. Readmitted at 6 months for investigation of poor weight gain. Noted to be cyanosed and breathless. Heart appeared large on chest $x$-ray but TGV measurement was less than $30 \%$ predicted. Arterial oxygenation did not improve in $100 \%$ oxygen, but improved significantly when continuous positive airway pressure was applied, supporting the suggestion that the clinical problem was mainly due to reduced lung volume.

Thoracic dystrophy. Case 13. Term, normal delivery; birthweight $3.8 \mathrm{~kg}$. Noted to have a small chest at birth. Admitted aged 3 months for investigation of tachypneoa and cyanosis during feeds. TGV $50 \%$ predicted.

Prolonged ventilation studies. In these 3 infants serial TGV measurements were made to assess the effect of long periods of IPPV on lung volume.
Case 14. Admitted on first day of life with oesophageal atresia, tracheo-oesophageal fistula, and ventricular septal defect. Did well initially after repair of the atresia and ligation of the fistula, but then developed respiratory difficulty and required intermittent periods of IPPV. Condition deteriorated and 4 months' continuous IPPV was required, during which time TGV rose from $50 \%$ predicted to over $200 \%$ predicted. Patient died and parental consent for necropsy was not obtained.

Case 15. Born by caesarean section at 37 weeks' gestation. Birthweight $3 \cdot 1 \mathrm{~kg}$. Cyanosed at birth; intubated, resuscitated, and transferred to this hospital. Cardiac arrest occurred on admission, responding to external cardiac massage and IPPV. Cardiac catheterization excluded congenital heart disease but showed desaturated pulmonary venous blood. $X$-ray showed ground glass appearance. Infant needed 4 months' IPPV during which time TGV rose from $<20 \%$ predicted to slightly above normal. Died aged 4 months, necropsy examination showing bronchopulmonary dysplasia and cor pulmonale.

Case 16. Term, normal delivery; birthweight $2.9 \mathrm{~kg}$. Respiratory distress from birth. Intubated and ventilated from 4th day of life. Angiocardiogram showed atrioventricular canal defect. Tracheostomy performed and IPPV used almost continuously until death from suppurative meningitis at age 4 months. TGV remained reduced throughout life, during most of which congestive cardiac failure was present. Necropsy examination confirmed the diagnosis of atrioventricular canal, meningitis, and pulmonary congestion.

\section{Results}

In Fig. 2 the relation of TGV to weight, length, age, and chest circumference in the 42 studies on healthy infants is shown together with the results of regression analysis. The line of the closest fit, calculated by the sum of least squares, is also shown together with $2 \mathrm{SD}$ about the mean. The best correlation is found between TGV and length $(r=0.712)$ and the relation is expressed by the formula $\mathrm{TGV}=5.5$ (length-141.6), with a coefficient of variation of $11.3 \%$. There is also good correlation between $\mathrm{TGV}$ and weight, chest circumference, and age, but height is a more reliable parameter than weight in sick children and infants. Results obtained in the present study for TGV in relation to length are compared with other published data for young children outside the neonatal period in Fig. 3.

Results of TGV measurements in the 16 children with abnormal lung function are shown in the Table, together with predicted normal TGV values obtained from the present study on normal children. 

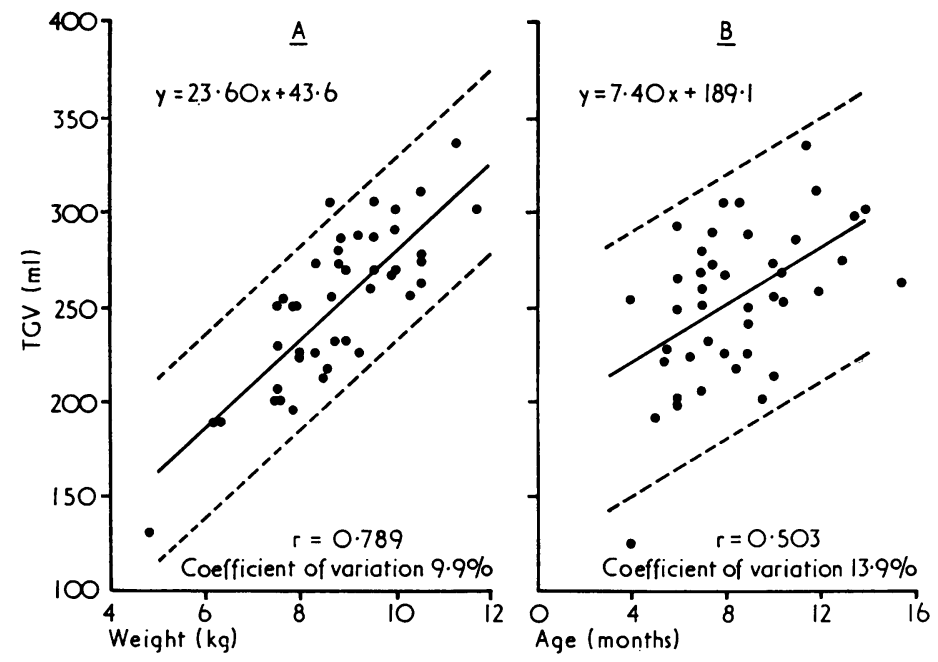

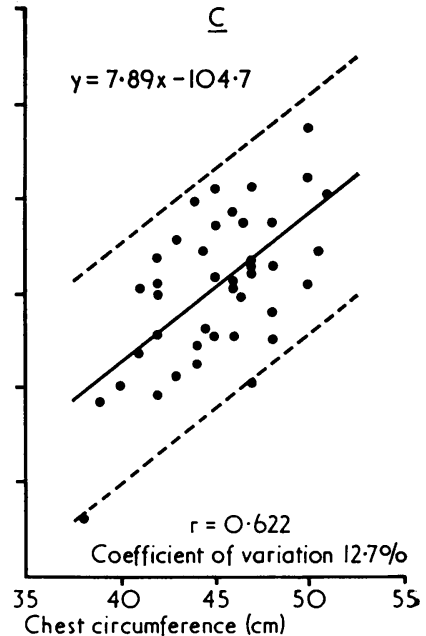

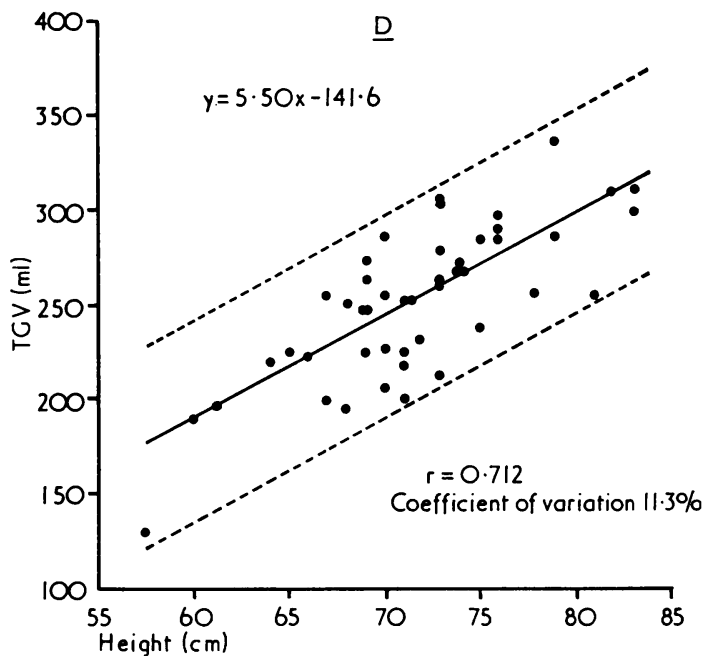

FIG. 2.-Relationship of TGV to $(A)$ weight, $(B)$ age, $(C)$ chest circumference, and $(D)$ height in 42 studies on healthy infants.

\section{Discussion}

Chest $x$-ray and arterial blood gas analysis are likely to remain the most useful investigations in severe lung disease in infancy and early childhood, but other lung function tests may help in the diagnosis and sometimes throw light on the underlying pathophysiology. Thoracic gas volume (TGV) seems to be one of the most satisfactory of the available tests of lung mechanics. Resis- tance measurements vary widely even in the course of one study and the published range of normal data is difficult to interpret. Dynamic compliance is difficult to interpret in rapidly breathing infants especially if there is obstruction with increased resistance to air flow, when falsely low values may be obtained (Comroe et al., 1962). Compliance values become more meaningful when expressed in relation to $\mathrm{TGV}$.

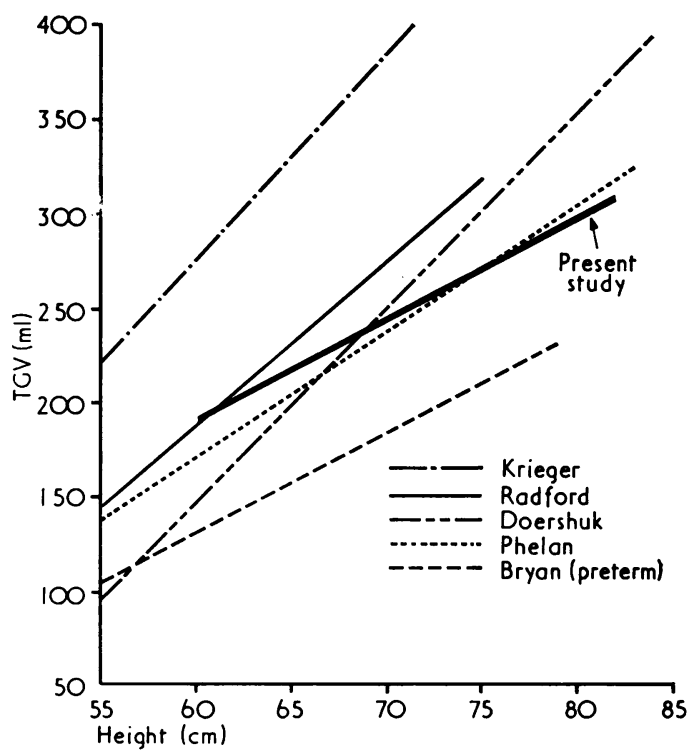

FIG. 3.-Results of TGV in relation to height in the present study compared with other published data for young children. 
To interpret pathological findings some idea of the normal range is necessary. To date $104 \mathrm{TGV}$ values have been reported on 80 infants aged 1 month to 2 years (Krieger, 1966; Phelan and Williams, 1969a; Doershuk et al., 1970; Radford, 1974). The results of the present study show a good correlation between TGV and weight, length, chest circumference, and age in normal children $(P<0.001)$. The 35 results reported add substantially to available normal values. Though there have been extensive lung function studies performed on neonates, older children have been less frequently studied because of the need for sedation and technical difficulties related to increasing size. Very sick infants and young children are even more difficult to study.

TGV measurements are reproducible. The mean coefficient of variation between measurements for individuals in the present study was $7.4 \%$ for normals and $6 \%$ for abnormals. Radford (1974) found a mean coefficient of variation between measurements of $10.1 \%$ in 5 healthy infants. In each of the infants in his study $10 \mathrm{TGV}$ measurements were made over a period of 1 hour.

TGV may be reduced, often in association with low pulmonary compliance, in many clinical situations. Reduced TGV is frequently seen in the presence of pulmonary infection, but is also reported here in respiratory distress syndrome of the newborn and in association with chest cage abnormalities. Major surgery, particularly cardiac, may be followed by severe reduction in TGV. Continuous positive airway pressure has been shown to counter this reduction in lung volume (Hatch, 1976) and in 3 of the patients in the present series TGV increased during a period of mechanical ventilation of the lungs. Prolonged periods of mechanical ventilation may be associated with hyperinflation probably from damage to lung tissue (Barnes et al., 1969). In Case 14 this increasing hyperinflation was confirmed by serial TGV measurements, but in Cases 15 and 16 lung volume did not rise above normal despite prolonged IPPV at high inflating pressures.

Doershuk, Fisher, and Matthews (1974) and Phelan et al. (1969) reported increased TGV in infants and young children with cystic fibrosis. The Melbourne group have also studied infants with 'recurrent asthmatic bronchitis' (Phelan and Williams, 1969b) and found an increased TGV in 5 out of 11 infants under 6 months of age. We have found TGV to be increased in almost all wheezy babies we have studied, and 2 such babies are described here. We also report increase in TGV in babies with a variety of diseases, in most of which small airways disease is a major feature.

\section{REFERENCES}

Barnes, N. D., Glover, W. J., Hull, D., and Milner, A. D. (1969). Effects of prolonged positive-pressure ventilation in infancy. Lancet, 2, 1096.

Becker, M. J., and Koppe, J. G. (1969). Pulmonary structural changes in neonatal hyaline membrane disease treated with high pressure artificial respiration. Thorax, 24, 689.

Bryan, M. H., Hardie, M. J., Reilly, B. J., and Swyer, P. R. (1973). Pulmonary function studies during the first year of life in infants recovering from the respiratory distress syndrome. Pediatrics, 52, 169.

Comroe, J. H., Jr., Forster, R. E., DuBois, A. B., Briscoe, W. A., and Carlsen, E. (1962). The Lung, Clinical Physiology and Pulmonary Function Tests, 2nd ed., p. 167. Year Book Medical Publishers, Chicago.

Doershuk, C. F., Fisher, B. J., and Matthews, L. W. (1974). Specific airway resistance from the perinatal period into adulthood. Alterations in childhood pulmonary disease. American Review of Respiratory Diseases, 109, 542.

Doershuk, C. F., Downs, T. D., Matthews, L. W., and Lough, M. D. (1970). A method for ventilatory measurements in subjects 1 month-5 years of age: normal results and observations in disease. Pediatric Research, 4, 165.

DuBois, A. B., Botelho, S. Y., Bedell, G. N., Marshall, R., and Comroe, J. H., Jr. (1956). A rapid plethysmographic method for measuring thoracic gas volume: comparison with a nitrogen washout method for measuring functional residual capacity in normal subjects. Fournal of Clinical Investigation, 35, 322.

Hatch, D. J. (1976). Respiratory measurement in infancy. Modern Trends in Anaesthesia. Series 4. Paediatric Anaesthesia. Ed. by T. C. Gray and G. J. Rees. Butterworths, London (in press).

Holzel, A., Bennett, E., and Vaughan, B. F. (1956). Congenital lobar emphysema. Archives of Disease in Childhood, 31, 216.

Krieger, I. (1966). Thoracic gas volume in infancy. American Fournal of Diseases of Children, 111, 393.

Mead, J. (1961). Mechanical properties of lungs. Physiological Reviews, 41, 281.

Northway, W. H., Jr., Rosan, R. C., and Porter, D. Y. (1967). Pulmonary disease following respirator therapy of hyaline membrane disease. New England fournal of Medicine, 276, 357.

Phelan, P. D., and Williams, H. E. (1969a). Ventilatory studies in healthy infants. Pediatric Research, 3, 425.

Phelan, P. D., and Williams, H. E. (1969b). Studies of respiratory function in infants with recurrent asthmatic bronchitis. Australian Paediatric Fournal, 5, 187.

Phelan, P. D., Gracey, M., Williams, H. E., and Anderson, C. M. (1969). Ventilatory function in infants with cystic fibrosis. Archives of Disease in Childhood, 44, 393.

Radford, M. (1974). Measurement of airway resistance and thoracic gas volume in infancy. Archives of Disease in Childhood, 49, 611 .

Stokes, C. R., Taylor, B. W., and Turner, M. W. (1974). Association of house-dust and grass-pollen allergies with specific IgA antibody deficiency. Lancet, 2, 485.

Taylor, B. W., Norman, A. P., Orgel, H. A., Stokes, C. R., Turner, M. W., and Soothill, J. F. (1973). Transient IgA deficiency and pathogenesis of infantile atopy. Lancet, 2, 111.

Williams, H. E. (1973). Inhalation pneumonia. Australian Paediatric fournal, 9, 279.

Wilson, M. G., and Mikity, V. G. (1960). A new form of respiratory disease in premature infants. American fournal of Diseases of Children, 99, 489.

Correspondence to Dr. D. J. Hatch, The Hospital for Sick Children, Great Ormond Street, London WC1N $3 \mathrm{JH}$. 